Check for updates

Cite this: RSC Adv., 2019, 9, 7457

\title{
Enhanced performance of PTB7-Th:PCBM based active layers in ternary organic solar cells $\uparrow$
}

\author{
Govinda Lakhotiya, ${ }^{* a b}$ Namdeo Belsare, ${ }^{\text {b }}$ Sudhir Arbuj, ${ }^{c}$ Bharat Kale (D) ${ }^{c}$ \\ and Abhimanyu Rana (D) *d
}

\begin{abstract}
The present study aims at understanding the role of incorporating $\mathrm{Cu}_{2} \mathrm{~S}$ nanocrystals (NCs) as a third component in ternary organic solar cells. Ternary photoactive blends consisting of conjugated polymer poly[4,8-bis(5-(2-ethylhexyl)thiophen-2-yl)benzo[1,2-b;4,5-b']dithiophene-2,6-diyl-alt-(4-(2-ethylhexyl)3-fluorothieno[3,4-b]thiophene-)-(2-carboxylate-2-6-diyl)] (PTB7-Th), fullerene derivative phenyl- $\mathrm{C}_{71}$ butyric acid methyl ester (PCBM) and different wt\% of $\mathrm{Cu}_{2} \mathrm{~S} N C s$ were formulated and were employed to fabricate ternary OSCs having a device architecture of ITO/ZnO/PTB7-Th: $\mathrm{Cu}_{2} \mathrm{~S} \mathrm{NCs:PCBM/MoO} / \mathrm{Ag}$. It has been observed that with the addition of 3 wt\% of $\mathrm{Cu}_{2} \mathrm{~S} N C s$, an improved power conversion efficiency (PCE) of $8.20 \%$ is obtained against the PCE of $6.96 \%$ for reference devices. EIS measurements and AFM studies suggests that the presence of $\mathrm{Cu}_{2} \mathrm{~S} \mathrm{NCs}$ facilitates formation of cascading energy levels, provides smoother surfaces and helps in suppressing trap-assisted recombination.
\end{abstract}

Received 28th October 2018

DOI: 10.1039/c8ra08919a

rsc.li/rsc-advances

tunable band-gaps which can be tuned to make it complimentary to the absorption of donor polymer and high charge carrier mobility and excellent charge transport properties which can certainly improve the charge collection. ${ }^{\mathbf{1 6}-18}$ Further, easy way of synthesis of semiconducting NCs using solution chemistry like wet-chemical synthesis and microwave synthesis is certainly helping to realize the goal of fabricating high PCE OSCs using screen printing, inkjet printing and roll-to-roll printing, and adaptability to flexible plastic substrates. ${ }^{19-23}$

In the past, many metallic and semiconducting NCs have been added in ternary photoactive blends of P3HT and PCBM giving the PCE less than 5\% in most of the cases. ${ }^{24-32}$ Some of the best known reported PCE of reference cell and best performing device upon the addition of optimum concentration of CdSe, CdS, CdTe, $\mathrm{ZnO}, \mathrm{Cu}_{2} \mathrm{~S}$ and $\mathrm{FeS}_{2}$ was found to be $3.5 \%$ and $4.2 \%, 0.74 \%$ and $0.95 \%, 0.72 \%$ and $0.79 \%, 2.78 \%$ and $3.39 \%$, $1.46 \%$ and $3.39 \%$ and $2.37 \%$ and $2.89 \%$ respectively. ${ }^{24-32}$ Recently, Sharma et al. $^{33}$ have demonstrated the use of microwave synthesized CdS nanoparticles in one of the efficient photoactive blend matrix consisting of PTB7:PCBM highlighting the increased PCE of OSCs from $6.44 \%$ to $7.14 \%$ upon the addition of optimum concentration of CdS nanoparticles. Although this is good PCE when compared to the previously reported P3HT:PCBM based ternary photoactive blend but it involves the use of toxic, hazardous and rare earth elements like cadmium and therefore can not be used for large scale fabrication.

In the present study, we have demonstrated the fabrication of high efficiency ternary OSCs by employing $\mathrm{Cu}_{2} \mathrm{~S}$ NCs as third component in one of the well-studied photoactive blend comprised of conjugated polymer PTB7-Th (poly[4,8-bis(5-(2-

\footnotetext{
${ }^{a}$ Department of Physics, Jankidevi Bajaj College of Science, Wardha 442001, India. E-mail: lakhotiya.govinda@gmail.com

${ }^{b}$ Department of Physics, Vidyabharati Mahavidyalaya, Amravati 444602, India

${ }^{c}$ Centre for Materials for Electronics Technology, Panchwati, Off Pashan Road, Pune 411008, India

${ }^{d}$ School of Engineering and Technology, BML Munjal University, Gurgaon 122413, India.E-mail: rana.abhimanyu@gmail.com

$\dagger$ Electronic supplementary information (ESI) available. See DOI: 10.1039/c8ra08919a
} 


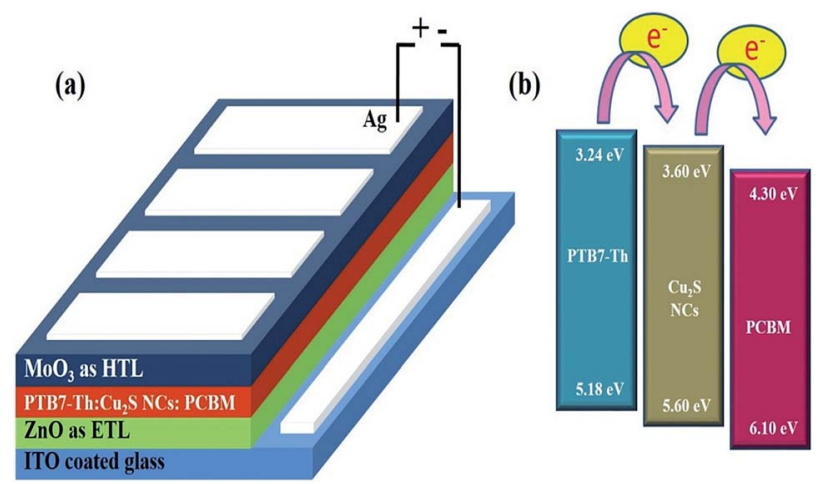

Fig. 1 (a) Schematic highlighting device architecture ITO/ZnO/PTB7$\mathrm{Th}: \mathrm{Cu}_{2} \mathrm{~S} \mathrm{NCs:PCBM} / \mathrm{MoO}_{3} / \mathrm{Ag}(\mathrm{b})$ energy levels of materials used in the solar cell device.

ethylhexyl)thiophen-2-yl)benzo[1,2-b;4,5- $b^{\prime}$ ]dithiophene-2,6-diylalt-(4-(2-ethylhexyl)-3-fluorothieno[3,4-b]thiophene-)-(2-

carboxylate-2-6-diyl)]) and fullerene derivative PCBM (phenyl- $\mathrm{C}_{71^{-}}$ butyric acid methyl ester). Apparently, $\mathrm{Cu}_{2} \mathrm{~S}$ consists of earth abundant and eco-friendly elements and also exhibit unusual properties such as high thermal and photo-chemical stability, broad absorption up to near IR range, high fluorescence quantum yields, high charge carrier mobilities and high electron affinities. ${ }^{34,35}$ Moreover, conduction band of $\mathrm{Cu}_{2} \mathrm{~S}$ is located around $3.60 \mathrm{eV}$ and lies between the LUMO of donor polymer PTB7-Th and fullerene acceptor PCBM. ${ }^{35,36}$ Thus, it is expected to form type II heterojunction with PTB7-Th and PCBM and can act as an electron cascade between them. This makes it more promising and interesting for this photoactive blend in comparison to other semiconducting NCs. However, to the best of our knowledge, there is no report on using $\mathrm{Cu}_{2} \mathrm{~S}$ as a third component with PTB7-Th:PCBM polymers based OSCs. Here, we have studied the role of $\mathrm{Cu}_{2} \mathrm{~S}$ NCs as third component by varying the concentration of $\mathrm{Cu}_{2} \mathrm{~S}$ NCs in the photoactive blend of PTB7-Th:PCBM. With the inverted geometry of the devices and the addition of optimum wt $\%$ of $^{-\mathrm{Cu}_{2} \mathrm{~S}}$ NCs, improved PCE of $8.20 \%$ is obtained as against the $6.96 \%$ for reference device. The obtained results are explained by electrochemical impedance spectroscopy (EIS) and atomic force microscopy (AFM) studies.

\section{Experimental}

\subsection{Synthesis of $\mathrm{Cu}_{2} \mathrm{~S}$ NCs}

The synthesis of copper(I) sulfide nanocrystals (NCs) was performed using hot injection technique whose protocol was developed by Alivisatos et al..$^{34}$ It deals with the chemistry of copper(II) acetylacetonate and ammonium diethyldithiocarbamate in a mixed solvent of dodecanethiol and oleic acid whose detailed procedure can be found somewhere else. ${ }^{34}$ Isopropanol and toluene were used for washing to get the precipitate of required NCs and were centrifuged with $5000 \mathrm{rpm}$ for $10 \mathrm{~min}$.
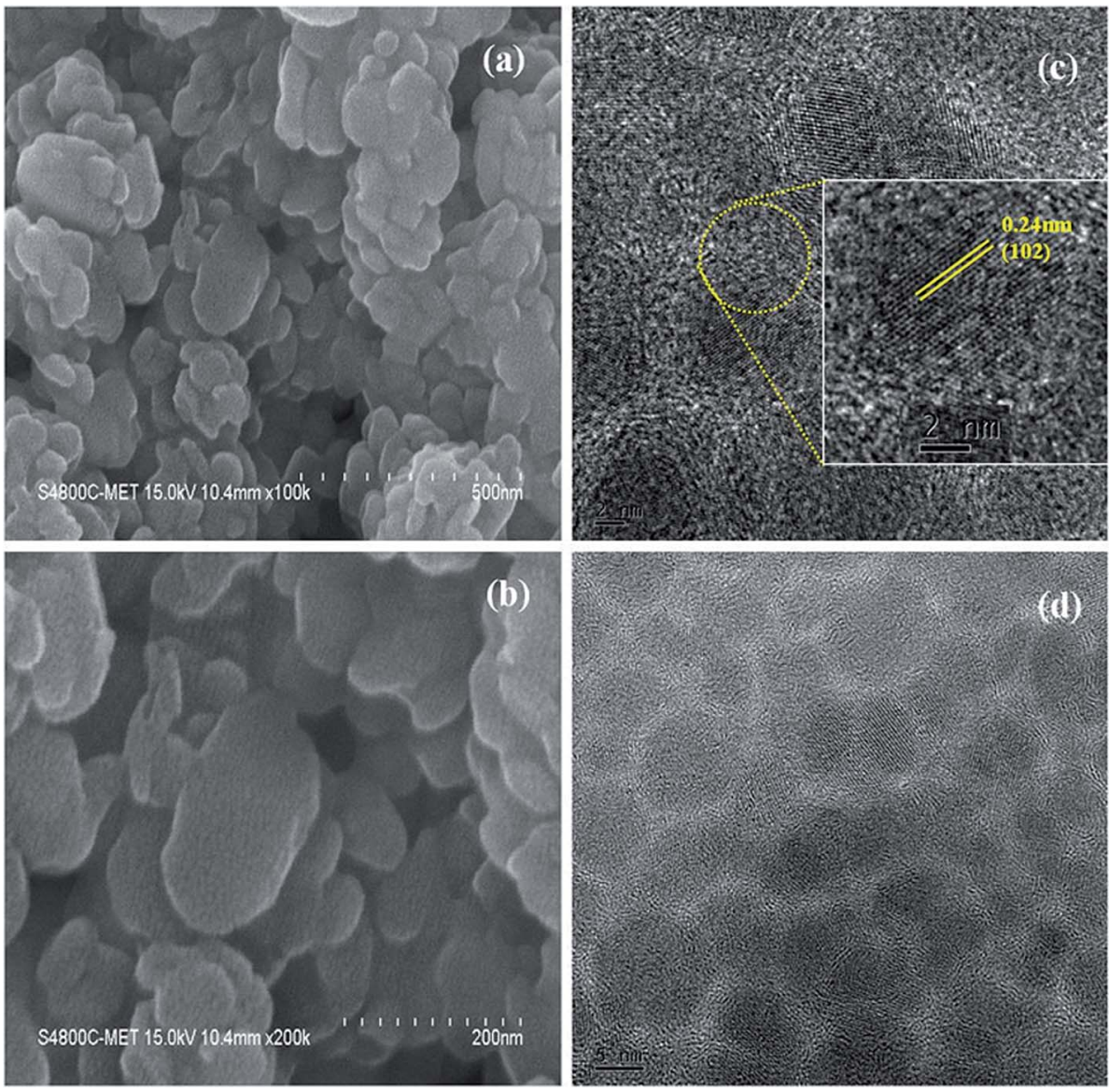

Fig. 2 ( $a$ and b) FESEM images and ( $c$ and d) HRTEM images of as synthesized $\mathrm{Cu}_{2} \mathrm{~S}$ NCs. 


\subsection{Material characterization and device fabrication}

For morphological studies, we have analyzed field emission scanning electron microscope (FESEM) images and high resolution transmission electron microscopy (HRTEM) images at different magnification. FESEM images were recorded using Hitachi's (S4800) field emission electron microscope which was operated at $30 \mathrm{kV}$ and HRTEM images were recorded using JEOL FS2200-FEG operating at $200 \mathrm{kV}$. $\mathrm{Cu}_{2} \mathrm{~S}$ nanocrystals (NCs) were also characterized for its phase purity by X-ray diffraction (XRD) technique using Rigaku's Miniflex 600 X-ray diffractometer which was operated at $40 \mathrm{kV}$ and $30 \mathrm{~mA}$ using $\mathrm{Cu} \mathrm{K}_{\alpha} \mathrm{X}$-rays $(1.54$ $\AA$ ). Optical property of $\mathrm{Cu}_{2} \mathrm{~S}$ NCs was studied using UV-vis absorption spectrophotometer using Shimadzu 1800.

Devices were fabricated as per the schematic shown in the Fig. 1(a) and involves depositions of different layers. Mainly PTB7-Th, PCBM and $\mathrm{Cu}_{2} \mathrm{~S}$ NCs based binary/ternary photoactive layer was sandwiched between the $\mathrm{ZnO}$ (an electron transport layer) and $\mathrm{MoO}_{3}$ (a hole transport layer). A pre-cleaned and patterned ITO coated glass substrates is used as a transparent substrate. Sol-gel synthesized ZnO was spin coated over ITO at $2000 \mathrm{rpm}$ for $30 \mathrm{~s}$ and annealed at $200{ }^{\circ} \mathrm{C}$ for $15 \mathrm{~min}$ to obtain a film of $\sim 40 \mathrm{~nm} .{ }^{15}$ Photoactive blend is prepared using PTB7Th $\left(10 \mathrm{mg}\right.$ ), PCBM (15 mg) and varying amount of $\mathrm{Cu}_{2} \mathrm{~S}$ NCs in $1 \mathrm{ml}$ of chlorobenzene (CB) with $3 \% \mathrm{v} / \mathrm{v}$ of 1,8 diiodooctane (DIO) solvent. Ternary blend was subjected to vigorous overnight stirring at $50{ }^{\circ} \mathrm{C}$ in the dark before being spin coated over the ZnO layer. ${ }^{15 a}$ For ternary photoactive blend, some amount of PCBM is replaced by the equal amount of $\mathrm{Cu}_{2} \mathrm{~S}$ NCs. Photoactive blends were spin-coated at $1200 \mathrm{rpm}$ for $60 \mathrm{~s}$ to obtain a film of thickness $\sim 100 \mathrm{~nm}$ and was allowed to dry for $2 \mathrm{~h}$. At last, $10 \mathrm{~nm}$ $\mathrm{MoO}_{3}$ layer as a hole transport layer and $100 \mathrm{~nm}$ Ag electrode as an anode was deposited by thermal evaporation. Keithley 2600 source meter and a Newport solar simulator (model number 91160) with $\mathrm{AM} 1.5 \mathrm{G}$ spectral distribution at $1000 \mathrm{~W} \mathrm{~m}^{-2}$ intensity was used for $J-V$ characteristics of the fabricated devices. Bentham's PVE300 was used for external quantum efficiency (EQE) spectra of the devices where the active device area was fixed to $7 \mathrm{~mm}^{2}$. Atomic force microscopy (AFM) of the films of photoactive blends with the different wt $\%$ of $\mathrm{Cu}_{2} \mathrm{~S}$ NCs was carried out using Nanosurf's C 3000 model. The EIS studies were carried out using electrochemical work station. The frequency range was swept from $1 \mathrm{MHz}$ to $1 \mathrm{~Hz}$ and $20 \mathrm{mV}$ and AC signal was superimposed with various DC applied bias voltage.

\section{Results and discussion}

The schematic of full device configuration is shown in the Fig. 1(a) and the positions of conduction band and valance band of $\mathrm{Cu}_{2} \mathrm{~S}$ NCs with respect to HOMO and LUMO levels of donor polymer PTB7-Th and acceptor polymer PCBM has been shown in Fig. 1(b). To confirm the morphology, phase purity, crystal structure and optical properties of the synthesized $\mathrm{Cu}_{2} \mathrm{~S}$ NCs, we have recorded the FESEM and HRTEM images, XRD pattern and UV-vis absorption spectra. Fig. 2a-d shows FESEM and HRTEM images at two different magnifications. The recorded images suggest that the protocol used for the synthesis of NCs has yielded dumbbell shaped NCs having length and diameter less than $20 \mathrm{~nm}$. An inter-layer spacing of $0.198 \mathrm{~nm}$ and $0.24 \mathrm{~nm}$, as can be seen in the high magnification HRTEM image (Fig. 2(c)), corresponds to (110) and (102) planes of $\mathrm{Cu}_{2} \mathrm{~S}$ NCs respectively. XRD pattern and UV-vis absorption spectra shown in the Fig. S1(a and b) † confirms that the as synthesized NCs are phase pure and have wide absorption spectrum UV-visNIR region. This is in close agreement with the previous studies. ${ }^{28,34}$ Current density versus voltage $(J-V)$ characteristics used for the calculation of power conversion efficiency (PCE) of fabricated solar cell is shown in Fig. 3(a) and the corresponding external quantum efficiency (EQE) spectra is shown in Fig. 3(b). Various device parameters such as open circuit voltage $\left(V_{\mathrm{oc}}\right)$, short-circuit current $\left(J_{\mathrm{sc}}\right)$, fill factors (FF) and PCE with

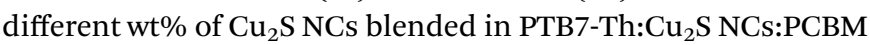
ternary OSCs is summarized in Table 1.

As can be seen in the Table 1 , for all the $w \mathrm{t} \%$ of $\mathrm{Cu}_{2} \mathrm{~S}$ NCs, there is very negligible change in the $V_{\text {oc }}$. To explain this, it is necessary to understand the origin of $V_{\mathrm{oc}}$. It is well known that the $V_{\text {oc }}$ mainly depends on the energy difference between the HOMO of the donor polymer and the LUMO of the acceptor polymer. In the present study, for all the composition of the
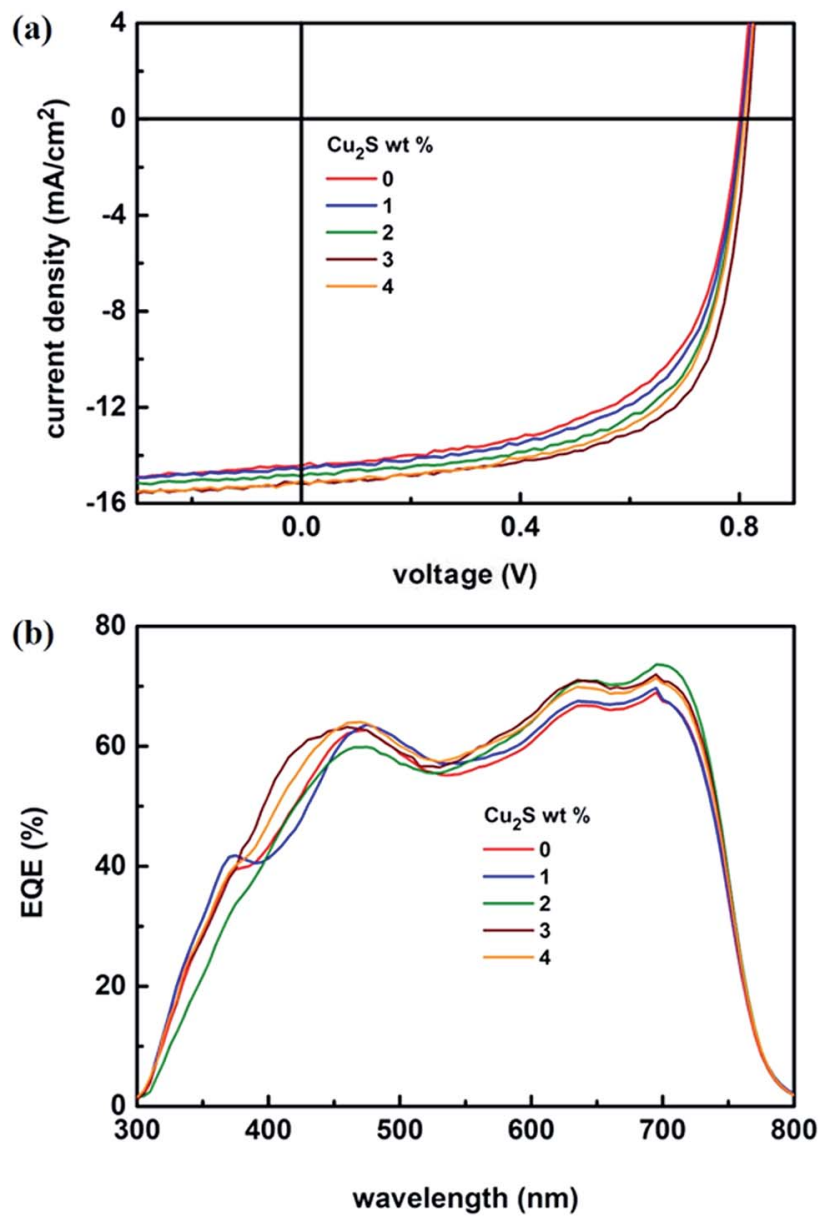

Fig. 3 (a) $J-V$ characteristics under illumination (AM 1.5G, one sun) and (b) EQE spectra of PTB7-Th: $\mathrm{Cu}_{2} \mathrm{~S}$ NCs:PCBM ternary OSCs with different wt\% of $\mathrm{Cu}_{2} \mathrm{~S} \mathrm{NCs}$. 
Table 1 Summary of J-V characteristics of PTB7-Th: $\mathrm{Cu}_{2} \mathrm{~S} N C s: P C B M$ devices with different wt\% of $\mathrm{Cu}_{2} \mathrm{~S}$ NCs

\begin{tabular}{lllll}
\hline $\mathrm{Cu}_{2} \mathrm{~S} \mathrm{NCs} \mathrm{wt} \%$ & $V_{\text {oc }}(\mathrm{mV})$ & Measured $J_{\mathrm{sc}}\left(\mathrm{mA} \mathrm{cm}{ }^{-2}\right)$ & Calculated $J_{\mathrm{sc}}{ }^{a}\left(\mathrm{~mA} \mathrm{~cm}^{-2}\right)$ & FF $(\%)$ \\
\hline $0 \%$ & 803 & 14.44 & 15.07 & 59.95 \\
$1 \%$ & 803 & 14.58 & 14.59 & 61.73 \\
$2 \%$ & 803 & 14.86 & 14.88 & $7.96(6.85)$ \\
$3 \%$ & 818 & 15.17 & 15.20 & 63.75 \\
$4 \%$ & 803 & 15.05 & 15.48 & 66.10 \\
\end{tabular}

${ }^{a}$ Calculated from EQE data. ${ }^{b}$ Average of the five devices.

ternary photoactive blend, added $w \mathrm{t} \%$ of $\mathrm{Cu}_{2} \mathrm{~S}$ NCs is very small as compared to the donor PTB7-Th and acceptor PCBM and therefore it is most likely that at most of the interfaces within the nano-morphology of the photoactive blend, interpenetrating networks of PTB7-Th and PCBM are in direct contact with each other. As a result, the $V_{\text {oc }}$ remains nearly same for all the composition. However, the scenario is different in the case of the $J_{\mathrm{sc}}$ and FF. It is observed that both $J_{\mathrm{sc}}$ and FF increases with the increase in the wt\% of $\mathrm{Cu}_{2} \mathrm{~S}$ NCs. This trend is observed till the concentration of $\mathrm{Cu}_{2} \mathrm{~S}$ NCs reaches its optimum value of $3 \mathrm{wt} \%$ and fabricated ternary device has demonstrated the PCE of $8.20 \%$ as against the PCE of $6.96 \%$ for reference device. This dramatic increase in the $J_{\mathrm{sc}}$ and FF and therefore the PCE can be justified by using the theory of charge transfer complex (CTC) ${ }^{37}$ It might be possible that the added $\mathrm{Cu}_{2} \mathrm{~S}$ NCs located at the interface of
PTB7-Th and PCBM may get bind with PTB7-Th:PCBM via dipole-dipole interaction and form a charge transfer complex (CTC) ${ }^{38}$ This is due to the formation of the electron cascade structure arises out of the well-placed conduction band of the $\mathrm{Cu}_{2} \mathrm{~S}$ between LUMO of donor polymer PTB7-Th and acceptor polymer PCBM. Also, it might be possible that presence of the $\mathrm{Cu}_{2} \mathrm{~S}$ NCs in the photoactive blend provides additional energetically favorable interfaces necessary for the exciton diffusion and formation of CT states. However, when the $\mathrm{Cu}_{2} \mathrm{~S}$ NCs concentration was further increased in the ternary photoactive blend, there is possibility that $\mathrm{Cu}_{2} \mathrm{~S}$ NCs might have agglomerated. This agglomeration might have decreased the additional energetically favorable interfaces thereby seriously affecting the process of exciton diffusion and CT states formation. As a result, it was observed that there is a decrease in the $J_{\mathrm{sc}}$ and FF and therefore
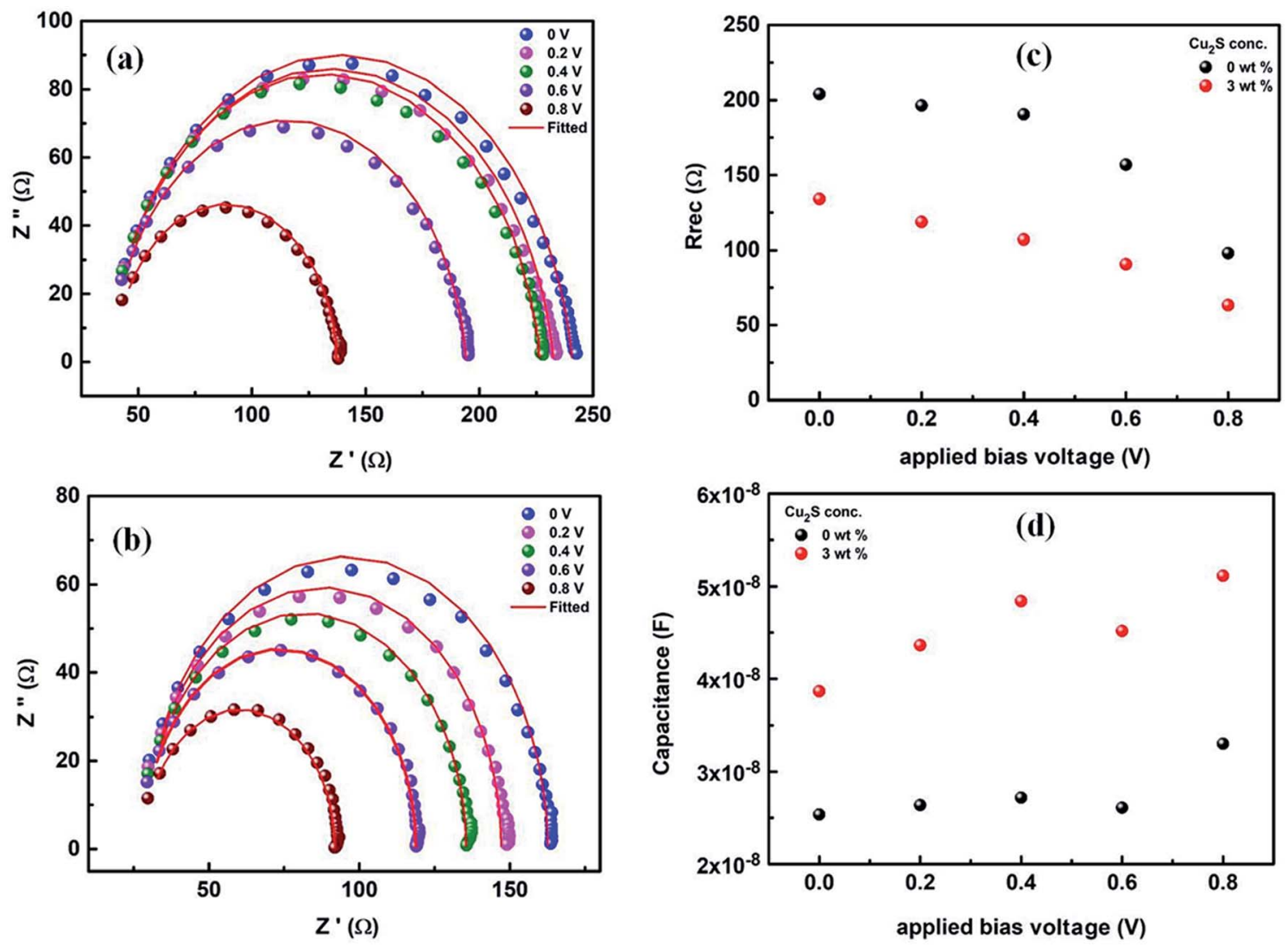

Fig. 4 (a) and (b) Nyquist plots of PTB7-Th:Cu $\mathrm{Cu}_{2} \mathrm{~S} \mathrm{NCs:PCBM} \mathrm{ternary} \mathrm{OSCs} \mathrm{with} 0$ and 3 wt\% of $\mathrm{Cu}_{2} \mathrm{~S}$ NCs respectively at different applied bias voltage $(c)$ recombination resistance $\left(R_{\text {rec }}\right)$ and $(d)$ chemical capacitance $\left(C_{\mu}\right)$ as a function of applied bias voltage for devices with 0 and 3 wt\% of $\mathrm{Cu}_{2} \mathrm{~S} \mathrm{NCs}$. 
the PCE. A similar trend was observed in the case of EQE spectra. The calculated values of $J_{\mathrm{sc}}$ from EQE are shown in the Table 1. Here, it is worth mentioning that the encapsulated ternary devices were quite stable for one month without significant change in the performance. We have also fabricated the PTB7$\mathrm{Th}: \mathrm{Cu}_{2} \mathrm{~S}$ NCs based binary device but found that the binary film of PTB7-Th: $\mathrm{Cu}_{2} \mathrm{~S}$ was very rough and comprised of so many pinholes. Thus, most of the fabricated devices got short and only few of them were measurable. Few of the measureable devices yielded PCE $<1 \%$. Therefore, this data has not been included in the manuscript. FF and $J_{\mathrm{sc}}$ is found to be highly compromised in these devices. It might be due to the poor dispersion of higher concentration of $\mathrm{Cu}_{2} \mathrm{~S}$ NCs $\left(15 \mathrm{mg} \mathrm{ml}^{-1}\right)$ in PTB7-Th matrix which might have tend to agglomerate to form scattering centers.

To get further insight about the improved performance parameters of the ternary OSCs with optimum wt\% (3\%) of $\mathrm{Cu}_{2} \mathrm{~S}$ NCs, EIS and AFM studies were carried out. Fig. 4(a) shows the Nyquist plots for both reference device $\left(\mathrm{Cu}_{2} \mathrm{~S} \mathrm{NCs}, 0 \mathrm{wt} \%\right)$ as well as the best performing device $\left(\mathrm{Cu}_{2} \mathrm{~S} \mathrm{NCs}, 3 \mathrm{wt} \%\right)$ respectively. It is observed that for both the systems, EIS spectra comprised of only one semi-circle. Therefore, they can be fitted by a simple $R_{\text {rec }}$. $C_{\mu}$ equivalent circuit, where $R_{\text {rec }}$ is a recombination resistance $\left(R_{\text {rec }}\right)$ and $C_{\mu}$ is the chemical capacitance $\left(C_{\mu}\right)$. However, as can be noticed, in both the cases, obtained Nyquist plots are not perfect semi-circles. This truncated semi-circle arises mainly due to the spatial inhomogeneity within the photoactive layer. This has to be taken into consideration and therefore for fitting purpose the capacitor element is replaced by constant phase elements (CPE).$^{39}$ Impedance for an ideal capacitor and CPE is given by eqn (1) and (2) respectively. ${ }^{\mathbf{4 0}}$ From above equations, it is apparent that CPE is equivalent to capacitance if $P$ equals 1 .

$$
\begin{gathered}
Z_{\mathrm{C}}=1 / \mathrm{i} \omega c \\
Z_{\mathrm{CPE}}=1 / \operatorname{CPE}(\mathrm{i} \omega)^{P} \\
n=\frac{1}{e} \int_{0}^{V_{\mathrm{oc}}} C_{\mu}(V) \mathrm{d} v
\end{gathered}
$$

After fitting, values of recombination resistance and chemical capacitance is obtained and is further used to calculate the value of carrier density using eqn (3). Response time representative of the recombination processes is calculated from the characteristic frequency $(\omega)$ at the top of the arc, where $2 \pi \omega=1$ / $\tau .^{\mathbf{4 0 , 4 1}}$ It is observed that for both the system recombination lifetime lies in order of $10^{-6} \mathrm{~s}$. Further, as can be seen in Fig. 4(c), recombination resistance is less in case of best performing device $\left(\mathrm{Cu}_{2} \mathrm{~S} \mathrm{NCs}, 3 \mathrm{wt} \%\right)$ when compared to reference device $\left(\mathrm{Cu}_{2} \mathrm{~S}\right.$ NCs, 0 wt\%). Additionally, using eqn (3), we have calculated the charger carrier density $(n)$ for both the systems using the capacitance values shown in Fig. 4(d). It is found that carrier densities for best performing device $\left(\mathrm{Cu}_{2} \mathrm{~S}\right.$ NCs, $\left.3 \mathrm{wt} \%\right)$ and reference device $\left(\mathrm{Cu}_{2} \mathrm{~S} \mathrm{NCs}, 0 \mathrm{wt} \%\right)$ at $0.8 \mathrm{~V}$ is $\sim 5 \times 10^{17}$ (a)

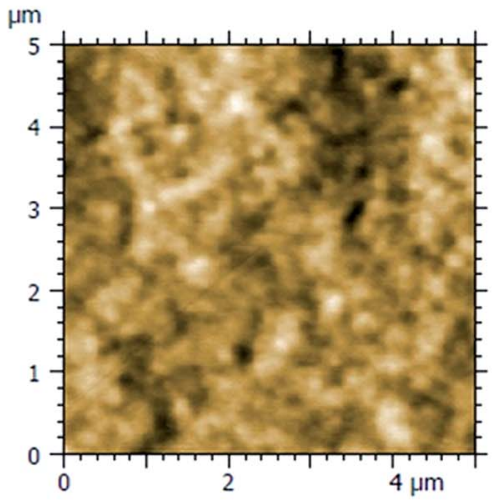

(c)

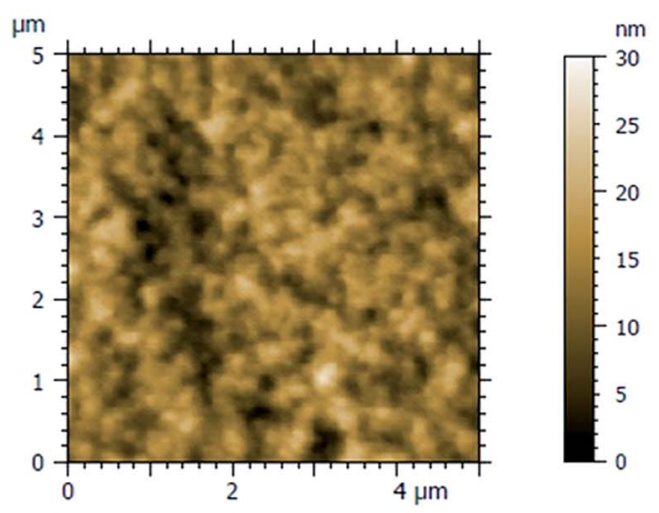

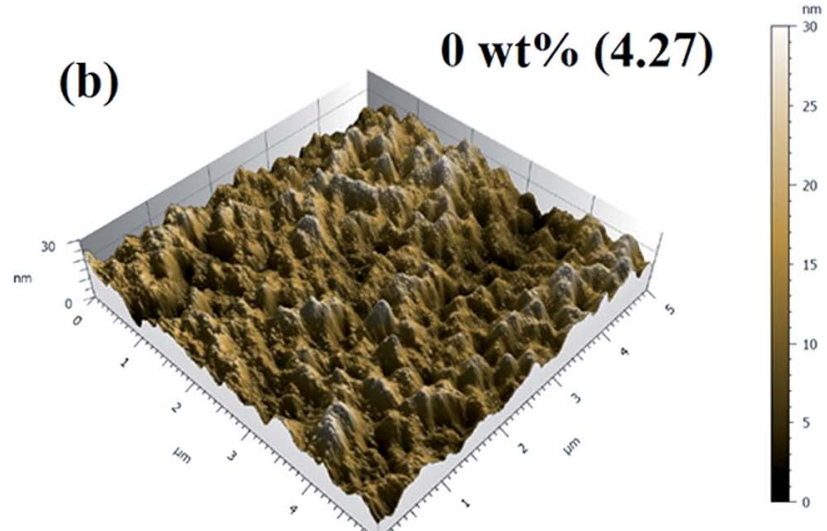

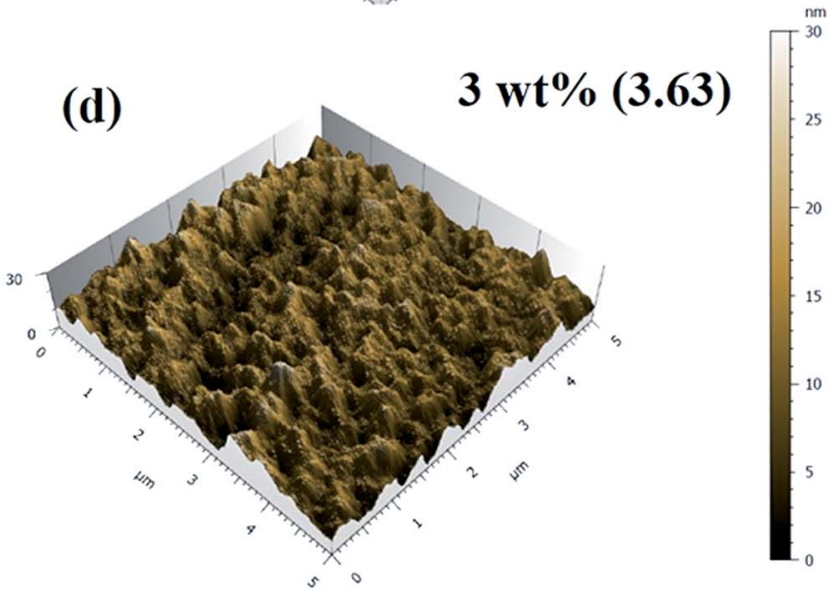

Fig. 5 2D and 3D AFM images of the films of PTB7-Th: $\mathrm{Cu}_{2} \mathrm{~S} \mathrm{NCs:PC} \mathrm{C}_{70} \mathrm{BM}$ photoactive blend with (a and b) 0 wt\% (c and d) 3 wt\% of $\mathrm{Cu}_{2} \mathrm{~S}$ NCs. 
$\mathrm{cm}^{-3}$ and $\sim 3 \times 10^{17} \mathrm{~cm}^{-3}$ respectively. Higher charge carrier density for the best performing device $\left(\mathrm{Cu}_{2} \mathrm{~S}\right.$ NCs, $\left.3 \mathrm{wt} \%\right)$ suggest that the charge collection is more efficient in this system. Thus, it can be said that the presence of $\mathrm{Cu}_{2} \mathrm{~S}$ NCs helps in improving the charge transfer and charge collection by providing electron cascade. This increase in the $J_{\mathrm{sc}}$ and $\mathrm{FF}$ and therefore the PCE supports the theory of charge transfer complex (CTC) ${ }^{37}$ wherein the formation of the electron cascade structure of the well-placed conduction band of the $\mathrm{Cu}_{2} \mathrm{~S}$ NCs between LUMO of donor polymer PTB7-Th and PCBM polymer plays a vital role. Also, it might be possible that the presence of $\mathrm{Cu}_{2} \mathrm{~S}$ NCs in the photoactive blend provides additional energetically favorable interfaces necessary for the exciton diffusion and formation of CT states.

AFM studies of the spin casted films of binary and ternary photoactive blends was carried out and 2D and 3D images are shown in the Fig. 5 and $\mathrm{S} 2 . \dagger$ As can be seen, films are quite smooth and does not have any pin-holes. The rms values of surface roughness are found to decrease from $\sim 4.27 \mathrm{~nm}$ for the films with $0 \mathrm{wt} \%$ of $\mathrm{Cu}_{2} \mathrm{~S}$ NCs to $\sim 3.63 \mathrm{~nm}$ for the films with $3 \mathrm{wt} \%$ of $\mathrm{Cu}_{2} \mathrm{~S}$ NCs. However, with the further increase in the concentration of $\mathrm{Cu}_{2} \mathrm{~S}$ NCs, rms surface roughness increases to $3.77 \mathrm{~nm}$. This might be due to the possibility of inhomogeneous distribution/agglomeration of $\mathrm{Cu}_{2} \mathrm{~S}$ NCs in the matrix. Accordingly, this has decreased the additional energetically favorable interfaces thereby affecting the process of exciton diffusion and CT states formation. The shielding effect could be due to the higher concentration of NCs which inherently affects the transport of electron in the matrix. This might have increased the charge carrier recombination which ultimately reduces the PCE.

\section{Conclusion}

In conclusion, role of $\mathrm{Cu}_{2} \mathrm{~S}$ NCs as third component in ternary OSCs has been successfully investigated by varying the concentration of $\mathrm{Cu}_{2} \mathrm{~S}$ NCs in ternary photoactive blend comprised of PTB7-Th, PCBM and $\mathrm{Cu}_{2} \mathrm{~S}$ NCs. Fabricated ternary OSCs having a device architecture ITO/ZnO/PTB7-Th: $\mathrm{Cu}_{2} \mathrm{~S}$ NCs:PCBM $/ \mathrm{MoO}_{3} / \mathrm{Ag}$ has shown the improved PCE of $8.20 \%$ as against the PCE of $6.96 \%$ for the reference device. The improvement in the performance parameters has been explained on the basis of the EIS measurements and AFM studies which suggest that presence of $\mathrm{Cu}_{2} \mathrm{~S}$ NCs facilitates formation of cascading energy levels and thus helps in suppressing trap-assisted recombination.

\section{Conflicts of interest}

Authors declare no conflict of interest.

\section{Acknowledgements}

GL thanks Principal, Jankidevi Bajaj College of Science, Wardha and Principal, Vidyabharti College for providing instrumentation facility for the work. AR thanks VC, BML Munjal University, Gurgaon for providing the facilities for this work. GL and AR thank Ramakant Sharma, IIT Bombay for valuable discussion and help.

\section{References}

1 D. Wöhrle and D. Meissner, Adv. Mater., 1991, 3, 129-138.

2 H. Hoppe and N. S. Sariciftci, J. Biomed. Mater. Res., 2004, 19, 1924-1945.

3 S. Günes, H. Neugebauer and N. S. Sariciftci, Chem. Rev., 2007, 107, 1324-1338.

4 A. Pivrikas, N. S. Sariciftci, G. Juška and R. Österbacka, Prog. Photovoltaics, 2007, 15, 677-696.

5 Q. An, F. Zhang, J. Zhang, W. Tang, Z. Deng and B. Hu, Energy Environ. Sci., 2016, 9, 281-322.

6 J. H. Noh, S. H. Im, J. H. Heo, T. N. Mandal and S. I. Seok, Nano Lett., 2013, 13, 1764-1769.

7 T. Ameri, P. Khoram, J. Min and C. J. Brabec, Adv. Mater., 2013, 25, 4245-4266.

8 J. Zhang, Y. Zhang, J. Fang, K. Lu, Z. Wang, W. Ma and Z. Wei, J. Am. Chem. Soc., 2015, 137, 8176-8183.

9 R. Sharma, H. Lee, V. Gupta, H. Kim, M. Kumar, C. Sharma, S. Chand, S. Yoo and D. Gupta, Org. Electron., 2016, 34, 111117.

10 Y. Zhang, D. Deng, K. Lu, J. Zhang, B. Xia, Y. Zhao, J. Fang and Z. Wei, Adv. Mater., 2015, 27, 1071-1076.

11 F. Ongul, S. A. Yuksel, C. Allahverdi, S. Bozar, M. Kazici and S. Gunes, Spectrochim. Acta, Part A, 2018, 194, 50-56.

12 K. Borse, R. Sharma, H. Sagar, P. A. Reddy, D. Gupta and A. Yella, Org. Electron., 2017, 41, 280-286.

13 S. A. Yousaf, M. Ikram and S. Ali, Appl. Nanosci., 2018, 1, 1-9. 14 W. Luan, C. Zhang, L. Luo, B. Yuan, L. Jin and Y.-S. Kim, Appl. Energy, 2017, 185, 2217-2223.

15 (a) A. K. Kyaw, X. W. Sun, C. Y. Jiang, G. Q. Lo, D. W. Zhao and D. L. Kwong, Appl. Phys. Lett., 2008, 93.22, 221107; (b) C. Li, X. Sun, J. Ni, L. Huang, R. Xu, Z. Li, H. Cai, J. Li, Y. Zhang and J. Zhang, Sol. Energy, 2017, 155, 1052-1058.

16 I. Gur, N. A. Fromer, M. L. Geier and A. P. Alivisatos, Science, 2005, 310, 462-465.

17 W. U. Huynh, J. J. Dittmer and A. P. Alivisatos, Science, 2002, 295, 2425-2427.

18 D. J. Milliron, I. Gur and A. P. Alivisatos, MRS Bull., 2005, 30, 41-44.

19 C. J. Brabec and J. R. Durrant, MRS Bull., 2008, 33, 670-675. 20 X. Peng, J. Yuan, S. Shen, M. Gao, A. S. Chesman, H. Yin, J. Cheng, Q. Zhang and D. Angmo, Adv. Funct. Mater., 2017, 27(41), 1703704.

21 S. I. Na, S. S. Kim, J. Jo and D. Y. Kim, Adv. Mater., 2008, 20, 4061-4067.

22 X. Fan, J. Wang, H. Wang, X. Liu and H. Wang, ACS Appl. Mater. Interfaces, 2015, 7, 16287-16295.

23 Y. Lin, H. F. Dam, T. R. Andersen, E. Bundgaard, W. Fu, H. Chen, F. C. Krebs and X. Zhan, J. Mater. Chem. C, 2013, 1, 8007-8010.

24 C.-Y. Liu, Z. C. Holman and U. R. Kortshagen, Nano Lett., 2008, 9, 449-452.

25 M. Taukeer Khan, A. Kaur, S. Dhawan and S. Chand, J. Appl. Phys., 2011, 110, 044509. 
26 S. R. Gollu, R. Sharma, G. Srinivas, S. Kundu and D. Gupta, Org. Electron., 2014, 15, 2518-2525.

27 H.-C. Liao, C.-S. Tsao, T.-H. Lin, M.-H. Jao, C.-M. Chuang, S.-Y. Chang, Y.-C. Huang, Y.-T. Shao, C.-Y. Chen and C.-J. Su, ACS Nano, 2012, 6, 1657-1666.

28 B. J. Richardson, L. Zhu and Q. Yu, Sol. Energy Mater. Sol. Cells, 2013, 116, 252-261.

29 G. Itskos, A. Othonos, T. Rauch, S. F. Tedde, O. Hayden, M. V. Kovalenko, W. Heiss and S. A. Choulis, Adv. Energy Mater., 2011, 1, 802-812.

30 W. J. Beek, M. M. Wienk, M. Kemerink, X. Yang and R. A. Janssen, J. Phys. Chem. B, 2005, 109, 9505-9516.

31 P. V. Kamat, J. Phys. Chem. C, 2008, 112, 18737-18753.

32 M. Choi, H. Fu, W. Luan and Y.-S. Kim, IEEE Nanotechnol. Mater. Devices Conf., 2011, 482-483.

33 R. Sharma, S. Bhalerao and D. Gupta, Org. Electron., 2016, 33, 274-280.

34 Y. Wu, C. Wadia, W. Ma, B. Sadtler and A. P. Alivisatos, Nano Lett., 2008, 8, 2551-2555.
35 A. Baray-Calderón, R. Galindo, J. Maldonado, O. MartínezAlvarez, L. Acosta-Torres, J. Santos-Cruz, J. de la FuenteHernández and M. Arenas-Arrocena, MRS Online Proc. Libr., 2015, 1748.

36 S. H. Liao, H. J. Jhuo, Y. S. Cheng and S. A. Chen, Adv. Mater., 2013, 25, 4766-4771.

37 F. Bencheikh, D. Duché, C. M. Ruiz, J.-J. Simon and L. Escoubas, J. Phys. Chem. C, 2015, 119, 24643-24648.

38 S. Hong, H. Kang, G. Kim, S. Lee, S. Kim, J.-H. Lee, J. Lee, M. Yi, J. Kim and H. Back, Nat. Commun., 2016, 7, 10279.

39 A. Guerrero, N. F. Montcada, J. Ajuria, I. Etxebarria, R. Pacios, G. Garcia-Belmonte and E. Palomares, J. Mater. Chem. A, 2013, 1, 12345-12354.

40 T. M. Clarke, C. Lungenschmied, J. Peet, N. Drolet and A. J. Mozer, Adv. Energy Mater., 2015, 5, 1401345.

41 R. Sharma, V. Gupta, H. Lee, K. Borse, R. Datt, C. Sharma, M. Kumar, S. Yoo and D. Gupta, Org. Electron., 2018, 62, 441-447. 